\title{
Reviews
}

\section{J. KACPRZYK}

Multistage decision-making under fuzziness. Theory and Applications

Interdisciplinary Systems Research (S. Klaczko, Ed.) Vol. 79, Verlag TÜV Rheinland, Köln, 1983, 128 pages.

Decision-making in a fuzzy environment is now beginning to receive the kind of scholarly attention it deserves, and this book is an exceptionally important and successful example of this type of work.

Clearly distinct from more traditional monographs, which typically lead the reader through descriptions of different approaches to a theoretical analysis, this work, based on the author's findings, leads to practical applications.

The line of reasoning is dominated by the control paradigm. Postulating the usefulness of analysing in control-systemic terms any situation involving some directed influence aimed at attaining some desired outcomes, the book deals with time-invariant fuzzy systems, with nonfuzzy control.

Kacprzyk's book has nine chapters. It begins with an overview of decision-making, followed by an introduction of the theory of fuzzy sets and fuzzy systems. It concludes with applications. The five central chapters are each a discourse on multistage decision-making in a fuzzy environment (with fixed and specified termination time, with implicitly specified termination time, with fuzzy termination time, and with infinite termination time).

One interesting feature of this book is the introduction of relevant practical applications. An important example is the comparison of different socioeconomic development policies for a rural region suffering under the irreversible effects of the emigration of young people to urban regions. The emigration is mainly caused by a perceived

North-Holland

Human Systems Management 4 (1984) 241-244 poor quality of life. To stop the economic decay, the life quality is to be considerably improved to increase satisfaction. Since the region does not possess sufficient own funds, some external outlays are necessary. The problem is to determine these outlays and their temporal distribution over some planning horizon to best achieve the development goals. Fuzzy sets emerge as a tool for coupling feelings and perceptions of decision makers with data in numerical decision models.

The book elucidates the range of what we understand about decision-making in fuzzy environment and illustrates the advantages to be gained by opening the mind and allowing judgment and professional expertise to assume their rightful roles in problem evaluations. The author has made an excellent case against economic determinism by pointing out that 'feeling', as it relates to environment, may be just as important as other more readily measurable components. Preocupation with precision can be as intellectually inhibiting as medieval scholasticism, and sorting out the many ideas presented in this book may open up vistas and inspire a more concentrated search for integrated studies in which judgment and professional expertise are accorded the concern they merit.

Using no sophisticated mathematical formalism and keeping the discussion as constructive and algorithmic as possible, the text provides the reader with a methodology. Most of it was obtained at the Systems Research Institute of the Polish Academy of Sciences in Warsaw, Poland. Some particular topics were recently elaborated and refined while the author was visiting the Machine Intelligence Institute at the Hagan School of Business of Iona College in New Rochelle, NY, USA.

Today, management scientists, political economists and sociologists as well as behavior researchers make use of the services offered by systems research when working with quantitatively describable phenomena. They all use the possibilities provided by modern computers to increase the efficiency or the effectiveness of the human mind when processing empirical questions or open questions for the completion of theories using system 
analysis. This, however, requires a methodology of handling linguistic variables in the frameworks of mathematical models, no matter how complicated or how simple they are. This book is a step further on the way to the establishing of such a methodology. It describes, illustrates, and presents it in a way which is immediately understandable.

In one word, this is a book about Systems Management, a fledgling discipline which seeks to utilize vague or intuitive information within a logical framework, the next stage of evolution in management science, enabling managers to grapple with the complex, irreducible problems that present today's most challenging management problems. By blending logic with intuitition, systems management may permit us to overcome the limitations of our previous rigorous methods.

Systems Management is supported by a number of contemporary observers. Van Gigch (A Methodological comparison of the science, systems and metasystems paradigms, in: Int. Journal of Man-Machine Studies, 11, 1979) and Fiksel (Applications of fuzzy set and possibility theory to systems management, in: R. Yager (ed), Fuzzy Set and Possibility Theory, Pergamon Press, New York, 1982) among others, have argued that reason and intuition have to be coupled in order to provide a more realistic representation and investigation of management problems. The organismic world-view that characterizes systems management is a remergence of an ancient, pre-industrial, holistic perception of the universe. The advent of industrialization the mathematical and information sciences have led us into a mechanistic world-view which seems to limit our ability to understand our environment and to fully utilize our human faculties. Now the evolution of thought and the pressures of necessity are leading us back to a new appreciation of the power of intuition. Through systems management one can exploit that power without sacrificing the benefits of the rational, analytical approach. What more can a scientist ask for? Fiksel, for instance, considers that for the creative management scientist, a wealth of opportunities exist now to extend and apply these ideas.

Kacprzyk's book extends and applies these ideas. It is one of the first to do so in a very convincing manner. Some years ago when I tried the same adventure (C.V. Negiota: Management Applications of System Theory, Birkhauser Verlag, Basel, 1979) I was wondering, scared, whether somebody else would follow.

Kacprzyk convinced me that boldness and freshness can turn a work into a first rate reference. His book is not an overview of recent theories in decision making described in the jargon of fuzzy sets. A far better characterization is that of a research programme. An invitation to fundamentally investigate the development and application of structured conceptual frameworks for supporting and enhancing the management of complex systems with low reducibility, to use the Ficksel's definition of systems management.

Seen from the perspective of a research programme, this monograph will increase the depth of knowledge of those with a particular interest in, or a need to analyse, complex systems. However, this book is aimed at a large class of readers, from readers who have never studied this subject to those who are interested in extending their knowledge of it. A beautiful achievement, for which the author has to be congratulated.

Constantin NEGOIŢĂ City University of New york New York, NY 10021, U.S.A.

Kavasseri V. RAMANATHAN

Management Control in Nonprofit Organizations Wiley \& Sons, New York, 1982, 612 pages.

\section{R. ANTHONY and R. HERZLINGER}

Management Control in Nonprofit Organizations Irwin, Homewood, IL, rev. ed., 1980.

The above books are molded from the same cookie-cutter. They have the same title, much the same structure - text and cases - in addition to covering similar sets of issues. They both cover management control techniques in nonprofit organizations, a relatively new subject area. Increasingly, courses on this subject are being offered at a number of schools of business and public administration in the United States and abroad.

Ramanathan, in particular, stresses the social contract between the organization and its participants in the control process (i.e., the agency relationships between shareholders and management, different levels of management, and super- 
visors and subordinates). He views the 'social mission' of the organization as vital to its long-run existence.

Nowadays, it seems that organizations - business enterprises and nonprofit organizations - can ill-afford to be socially irresponsible. Failure to act socially responsibly is bound to have a detrimental effect on the organization's long-run performance, indeed on its survival. Management control systems should be concerned with agency relationships with a view towards monitoring the activities of the organization.

To a significant extent, Ramanathan embraces social accounting and accountability. To his credit, Ramanathan even touches upon welfare economics and considers the concept of a Pareto optimum, ${ }^{1}$ unlike most accounting writers. Ramanathan suggests that "moving toward a socially more acceptable Pareto-optimal equilibrium" reflects a better balance between economic growth and social welfare.

I should point out that the recent literature on the economics of social costs and benefits has pointed to the need of disclosing such data to the public, in order to optimize welfare. ${ }^{2}$ Information pertaining to social costs and benefits has generally been ignored in accounting, but it should be widely disseminated for the purpose of conveying useful data to the public. Omission of this data may well leave a significant part of the organisation's activities untold. The public is concerned about the performance of nonprofit organizations. After all, it is the public in the last analysis that allows such organizations to receive tax exempt-

1 As Jensen' observes: "It astonishes me how the unending discussions regarding what accounting should be can be carried on without the words Pareto Optimality ever being mentioned, much less used in any substantive sense even though there are often references to the interests of society. Instead, the discussion is couched in terms such as 'usefulness' which are essentially empty of content. The only way these issues can in fact even be answered is in terms of choices based on the real effects of various alternative actions on people, their behavior, their wealth, and their utilization of resources".

See M. Jensen, Reflections on the state of accounting research and the regulation of accounting, Stanford Lectures in Accounting, 1976, pp. 11-19.

2 See, for example, J. Ronen, Accounting for social costs and benefits, in: Objectives of financial statements, vol. 2, J. Cramer and G. Sorter (eds.) American Institute of CPAs, NY, 1974, pp. $317-340$. ions. Thus, it is a matter of self interest for organizations - nonprofit and profit - to furnish social disclosures, insofar as the presentation serves to enhance their public image.

Ramanathan provides an explicit, though far from unique, framework or model as the focal point for the book. Anthony, by contrast, furnishes a much-less refined, indeed simplistic, planning-control framework. Both approaches attempt, at least implicitly, to cross-pollinate various disciplines including, but not limited to: management, accounting, economics, and social psychology. The subject matter is, thus, interdisciplinary. Accordingly, from my perspective at least, a threshold level of knowledge in the relevant disciplines coupled with the ability to integrate the disciplines is desirable, in order to fully understand and apply the concepts set forth in these books.

Ramanathan's model has technical and behavioral dimensions. The technical dimension deals with the social mission of the organization, its broad goals, specific objectives, and norms. On the other hand, the behavioral dimension is concerned with planning, programming, budgeting, and execution of the goals and objectives as well as employee motivation.

Inasmuch as the application of management control to nonprofit organizations constitutes a relatively new field of endeavor, these books are blazing new trials. Special emphasis is placed on the behavioral dimension of control - even more so by Ramanathan than by Anthony. In control systems, we are concerned with achieving goal congruence and enhancing employee performance. While both books deal with the importance of participatory budgeting, neither one focuses on the fact that employee participation is not necessarily beneficial. It is only under specific circumstances that participation pays, i.e., morale and productivity improve. ${ }^{3}$

While both books stress the importance of budgeting and benefit-cost analysis, Ramanathan, in particular, gives the topic of Zero Base Budgeting (ZBB) short shift. It would be useful to see a comparative analysis between $\mathrm{ZBB}$ and

\footnotetext{
3 For an insightful analysis of this issue, see P. Brownell, Participation in the budgeting process: When it works and when it doesn't, Journal of Accounting Literature, Spring 1982, pp. 124-153.
} 
Planning/Programming/Budgeting/Systems (i.e., the predecessor of ZBB). However, no such analysis appears in either book. I am certain that controllers of nonprofit organizations would desire to see a more extensive analysis of ZBB in books of this type.

While the misuse of control surrogates (such as inputs, costs, and outcome indicators) is considered by Ramanathan, insufficient emphasis is placed on how multiple performance criteria might be used in order to avoid giving undue emphasis to any one surrogate. Additionally, Ramanathan does not give adequate attention to the importance of opportunity and imputed costs in the decisionmaking process; in this regard, Anthony does a superior job.

Since cases comprise about forty percent of each book, the rest of each volume furnishes a limited, and at times superficial, discussion of the issues. Perhaps more emphasis should have been placed on the theoretical framework underlying these works. While Ramanathan cites a number of articles, he could pay more attention to the academic literature on the topic areas with which the book deals. This criticism applies even more so to Anthony.

Despite their shortcomings, the authors of both books should be congratulated for providing an informative, stimulating, and important work. In view of the significant growth in the nonprofit sector in recent years, these tests are timely and worth recommending especially to current and prospective administrators of nonprofit organizations.

Robert BLOOM

College of Business and Economics University of Wisconsin Whitewater, WI 53190, U.S.A. 